Serge Marbacher Volker Neuschmelting Thilo Graupner Stephan M. Jakob Javier Fandino

\section{Prevention of delayed cerebral vasospasm by continuous intrathecal infusion of glycerol- trinitrate and nimodipine in the rabbit model in vivo}

Received: 8 July 2007

Accepted: 21 December 2007

Published online: 24 January 2008

(C) Springer-Verlag 2008

Electronic supplementary material

The online version of this article (doi:10.1007/s00134-008-0995-x) contains supplementary material, which is available to authorized users.

This study was supported by the Cerebrovascular Research Fund from the Departments of Neurosurgery and Intensive Care Medicine (account no. 34-160), University of Berne, Switzerland.

S. Marbacher - V. Neuschmelting •

T. Graupner · S. M. Jakob · J. Fandino ( $)$

University Hospital, Department

of Intensive Care Medicine,

Freiburgstrasse 10, 3010 Berne, Switzerland e-mail: javier.fandino@ksa.ch

Tel.: +41-62-8386693

S. Marbacher · V. Neuschmelting ·

T. Graupner · J. Fandino

University Hospital, Department

of Neurosurgery,

Freiburgstrasse 10, 3010 Berne, Switzerland

J. Fandino

Kantonsspital Aarau, Department

of Neurosurgery,

Aarau, Switzerland

\begin{abstract}
Objective: Intrathecal bolus administration of nitric oxide donors and calcium channel antagonists has been proposed to reduce cerebral vasospasm (CVS) in animal subarachnoid hemorrhage (SAH) models. Intrathecal continuous administration of these substances for CVS prevention has not been extensively evaluated. This study compared the efficacy of continuous intrathecal infusions of the NO donor glyceroltrinitrate and nimodipine in preventing delayed CVS associated with SAH in an animal model in vivo. Methods: New Zealand White rabbits were randomly assigned to six groups: no SAH/NaCl, no SAH/NO, no $\mathrm{SAH} /$ nimodipine, $\mathrm{SAH} / \mathrm{NaCl}$, $\mathrm{SAH} / \mathrm{NO}$, or SAH/nimodipine. Glyceroltrinitrate $(\mathrm{GTN})$ at $0.5 \mu \mathrm{g} / \mu \mathrm{l}$ $(0.5 \mu \mathrm{l} / \mathrm{h})$ or nimodipine at $0.2 \mu \mathrm{g} / \mu \mathrm{l}$ $(10 \mu \mathrm{l} / \mathrm{h})$ or $\mathrm{NaCl}$ was continuously infused into the cisterna magna via an Alzet osmotic pump from day 0 to day 5 after injection of $1.0 \mathrm{ml}$ autologous blood. The magnitude of spasm in the basilar artery was determined by comparison of pre- and posttreatment angiography
\end{abstract}

and was calculated as proportional change in intraluminal diameter based on automatic measurements. Results: A total of 55 experiments and 110 angiograms were performed. SAH was associated with vasoconstriction of the basilar artery ( $\mathrm{SAH} / \mathrm{NaCl}$ group $19.85 \pm 2.94 \%)$. Continuous intrathecal injection of GTN and nimodipine prevented SAH-induced CVS. There was significant prevention of CVS in animals treated with GTN (SAH/NO group $5.93 \pm 5.2 \%, n=11)$ and nimodipine (SAH/nimodipine group: $0.55 \pm 2.66 \%, n=9$ ). There was no significant difference between the treatment groups and controls in prevention of CVS. Conclusions: This study demonstrates that prophylactic continuous intrathecal administration of either GTN or nimodipine equally prevents $\mathrm{SAH}$-associated CVS in an animal model.

Keywords Subarachnoid hemorrhage - Vasospasm - Animal models . Nitric oxide $\cdot$ Nimodipine

\section{Introduction}

Symptomatic delayed cerebral vasospasm (DCV) develops in approx. $30 \%$ of patients after aneurysmal subarachnoid hemorrhage (SAH) and remains one of the major causes of serious morbidity and death [1,2]. Brain ischemic events secondary to cerebral vasospasm (CVS) classically occur 4-12 days after initial bleeding [3]. The exact cause of CVS is unknown despite awareness of the entity for almost half a century. Although the treatment protocol of hypervolemia, hemodilution, and hypertension ("triple- $\mathrm{H}$ therapy") in combination with intravenous nimodipine administration has had a substantial beneficial effect in CVS treatment [4], in some patients the protocol is not tolerated 
or is ineffective [5-7]. Despite our increased knowledge of the molecular basis of DCV following SAH no current treatment modalities offer prophylactic prevention. Preliminary case series in humans [8-11] and experimental studies in a variety of animal models [12-17] suggest that intrathecal administration of an NO donor would be an effective treatment for reversing CVS. Controlledrelease polymers such as diethyl-amine-triamine/NO and ethylene-vinyl acetate copolymer implanted in the subarachnoid space close to the experimental bleeding site serve as NO donors in most recent animal models with intrathecal administration of the drugs [12-18]. Furthermore, sodium nitroprusside (SNP) and glyceroltrinitrate (GTN) have served as NO donor to prevent CVS after SAH $[8-11,19,20]$.

Nimodipine, the most widely administered calcium channel blocker, is a dihydropyridine calcium channel antagonist that has been shown to decrease the incidence of overall cerebral infarction after $\mathrm{SAH}$ by $34 \%$ and the incidence of poor outcomes by $40 \%$ [21]. Whereas intravenous or oral administration of nimodipine does not appear to decrease the incidence of angiographic CVS [22, 23], intraoperative bathing of vessels in nimodipine solution and intrathecal bolus administration has demonstrated reversal of spasm and dilatation of nonspastic vessels, without changes in mean arterial blood pressure [24-29]. The present study compared the efficacy of continuous intrathecal infusions of the NO donor glyceroltrinitrate and nimodipine in preventing CVS in the rabbit SAH model in vivo.

\section{Materials and methods}

The protocol of this study was reviewed and approved by the Swiss Institutional Animal Care and Use Committee and meets the Swiss guidelines for laboratory animal use (Department of Veterinary Service, Berne, Switzerland, approval no. 125/05).

\section{Study design}

A total of 55 adult New Zealand White rabbits of either sex weighing $2.6-3.6 \mathrm{~kg}$ were randomly assigned to six experimental groups. The groups did not differ significantly in body weight, $\mathrm{PaCO}_{2}$, mean arterial blood pressure, or heart rate at baseline (day 0) or at follow-up (day 5; Table 1).

Anesthesia, monitoring, and killing

Induction of general anesthesia was performed by intramuscular administration of ketamine $(30 \mathrm{mg} / \mathrm{kg}$; Ketalar, $50 \mathrm{mg} / \mathrm{ml}$, Pfizer, Zurich, Switzerland) and $x y-$ lazine $(6 \mathrm{mg} / \mathrm{kg}$; Xylapan $20 \mathrm{mg} / \mathrm{ml}$, Vetoquinol, Bern, Switzerland). During surgery pain was evaluated periodically by toe-pinch. Postoperative pain relief was managed by subcutaneous administration of buprenorphine $(0.1-0.2 \mathrm{mg} / \mathrm{kg})$ for up to $36 \mathrm{~h}$ after SAH. Heart rate and blood pressure were monitored throughout the digital subtraction angiography (DSA) on day 0 and day 5 after experimental SAH. Intravascular pressures and heart rate were measured with a Camino multiparameter monitor (Integra, Plainsboro, NJ, USA). On the same days arterial blood gas status was analyzed to monitor oxygenation parameters from a collected arterial blood sample (ABL 725, Radiometer, Copenhagen, Denmark). The animals underwent daily clinical observation. The animals were killed on day 5 post-SAH induction under the same anesthetic as the angiography by intra-arterial bolus injection of sodium thiopenthal $(40 \mathrm{mg} / \mathrm{kg}$ ) (Pentothal, Ospedalia,
Table 1 Measurements of physiological parameters $\left(\mathrm{PaCO}_{2}\right.$, arterial carbon dioxide pressure; $\mathrm{PaO}_{2}$, arterial oxide pressure; $M A B P$, mean arterial blood pressure; $H R$, heart rate)

\begin{tabular}{|c|c|c|c|c|c|}
\hline & $\begin{array}{l}\text { Body } \\
\text { weight }(\mathrm{kg})\end{array}$ & $\begin{array}{l}\mathrm{PaCO}_{2} \\
(\mathrm{mmHg})\end{array}$ & $\begin{array}{l}\mathrm{PaO}_{2} \\
(\mathrm{mmHg})\end{array}$ & $\begin{array}{l}\text { MABP } \\
(\mathrm{mmHg})\end{array}$ & $\begin{array}{l}\text { HR } \\
\text { (per min) }\end{array}$ \\
\hline \multicolumn{6}{|c|}{ no $\mathrm{SAH} / \mathrm{NaCl}$} \\
\hline Day 0 & $3.6 \pm 0.1$ & $51.70 \pm 0.95$ & $50.52 \pm 8.6$ & $65.5 \pm 4.04$ & $162 \pm 5$ \\
\hline Day 5 & $3.6 \pm 0.1$ & $43.60 \pm 3.30$ & $57.20 \pm 1.3$ & $56.20 \pm 6.64$ & $174 \pm 7$ \\
\hline \multicolumn{6}{|c|}{ no SÅH/NO } \\
\hline Day 0 & $3.7 \pm 0.2$ & $44.00 \pm 1.97$ & $54.72 \pm 3.7$ & $64.33 \pm 2.89$ & $157 \pm 4$ \\
\hline Day 5 & $3.7 \pm 0.2$ & $45.75 \pm 7.34$ & $57.31 \pm 4.1$ & $55.33 \pm 4.96$ & $155 \pm 8$ \\
\hline \multicolumn{6}{|c|}{ no SAH/nimodipine } \\
\hline Day 0 & $2.7 \pm 0.1$ & $49.43 \pm 1.82$ & $63.24 \pm 4.2$ & $77.83 \pm 3.43$ & $178 \pm 10$ \\
\hline Day 5 & $2.7 \pm 0.1$ & $50.23 \pm 1.77$ & $61.04 \pm 4.9$ & $70.50 \pm 2.62$ & $181 \pm 6$ \\
\hline \multicolumn{6}{|l|}{$\mathrm{SAH} / \mathrm{NaCl}$} \\
\hline Day 0 & $3.8 \pm 0.2$ & $45.37 \pm 1.63$ & $67.27 \pm 5.2$ & $72.50 \pm 3.95$ & $163 \pm 4$ \\
\hline Day 5 & $3.8 \pm 0.2$ & $41.36 \pm 3.68$ & $63.07 \pm 4.1$ & $59.83 \pm 2.68$ & $171 \pm 7$ \\
\hline \multicolumn{6}{|l|}{$\mathrm{SAH} / \mathrm{NO}$} \\
\hline Day 0 & $3.8 \pm 0.1$ & $43.52 \pm 2.16$ & $64.80 \pm 3.2$ & $67.33 \pm 3.40$ & $179 \pm 5$ \\
\hline Day 5 & $3.8 \pm 0.1$ & $44.03 \pm 2.57$ & $62.98 \pm 8.5$ & $65.00 \pm 4.95$ & $163 \pm 7$ \\
\hline \multicolumn{6}{|c|}{ SAH/nimodipine } \\
\hline Day 0 & $3.1 \pm 0.2$ & $48.68 \pm 1.43$ & $67.05 \pm 3.4$ & $75.83 \pm 2.52$ & $191 \pm 9$ \\
\hline Day 5 & $3.1 \pm 0.2$ & $48.30 \pm 1.68$ & $74.07 \pm 6.5$ & $71.17 \pm 2.09$ & $178 \pm 7$ \\
\hline
\end{tabular}


Hünenberg, Switzerland). Postmortem examination of operative scars, pump, and tube position was performed to evaluate signs of infection and to affirm correct silicone catheter connection to the pump and unchanged catheter location within the subarachnoid space of the atlanto-occipital cistern.

\section{Angiography}

DSA was performed under general anesthesia on day 0 prior to SAH and on day 5 post-SAH. The rabbit's left (day 0) or right (day 5) subclavian artery was microsurgically exposed and cannulated using a $0.5 \mathrm{~mm}$ plastic tube. The catheter was introduced retrogradely and fixed distally to the origin of the vertebral artery. Subsequently the DSA was performed by intra-arterial bolus injection of nonionic iopamidol $(0.6 \mathrm{ml} / \mathrm{kg}$; Abott Laboratories, North Chicago, IL, USA) as contrast agent. Images of the vertebrobasilar system were obtained using a rapid sequential angiographic technique with the small focal spot at $66 \mathrm{kV}$, $125 \mathrm{~mA}$ (DFP 2000A, Toshiba, Japan). Measurement of each vessel was performed three times in a blinded fashion by using the automatic measurement tool of the ImagePro Discovery analysis software (MediaCybernetics, Silver Spring, MD, USA), and mean values were determined.

\section{Induction of experimental SAH}

Following baseline DSA on day 0, the atlanto-occipital membrane was exposed, and a 25-gauge needle was inserted into the cerebromedullar cistern. After relief of $1.0 \mathrm{ml} \mathrm{CSF}$ an equal amount of unheparinized autologous arterial blood was injected into the cistern under microscopic view. The rabbits were kept positioned at a $65^{\circ}$ angle head-down for 10 min to allow blood dissemination throughout the subarachnoidal space (Fig. 1).

\section{Miniosmotic pump implantation}

Depending on the study group, a miniosmotic pump $(0.5 \mu \mathrm{l} / \mathrm{h}$, Alzet Osmotic Pumps, Durect, Cupertino, CA, USA) containing $0.5 \mathrm{mg} / \mathrm{ml}$ GTN solution (Perlinganit, Schwarz Pharma, Münchenstein, Switzerland) or a miniosmotic pump $(10 \mu \mathrm{l} / \mathrm{h}$, Alzet $)$ containing $0.2 \mathrm{mg} / \mathrm{ml}$ nimodipine solution (Nimotop, Bayer HealthCare, Cologne, Germany) was implanted subcutaneously. Doseresponse curves of intrathecal GTN and nimodipine are not available. The dose of GTN was derived from studies in humans in which up to $8 \mathrm{mg} / 24 \mathrm{~h}$ was used for prophylaxis against vasospasm $[8,9]$. The $\mathrm{pH}$ value of the GTN and nimodipine solution was 7.35 and 7.4 , respectively. The dose of nimodipine was calculated from studies in

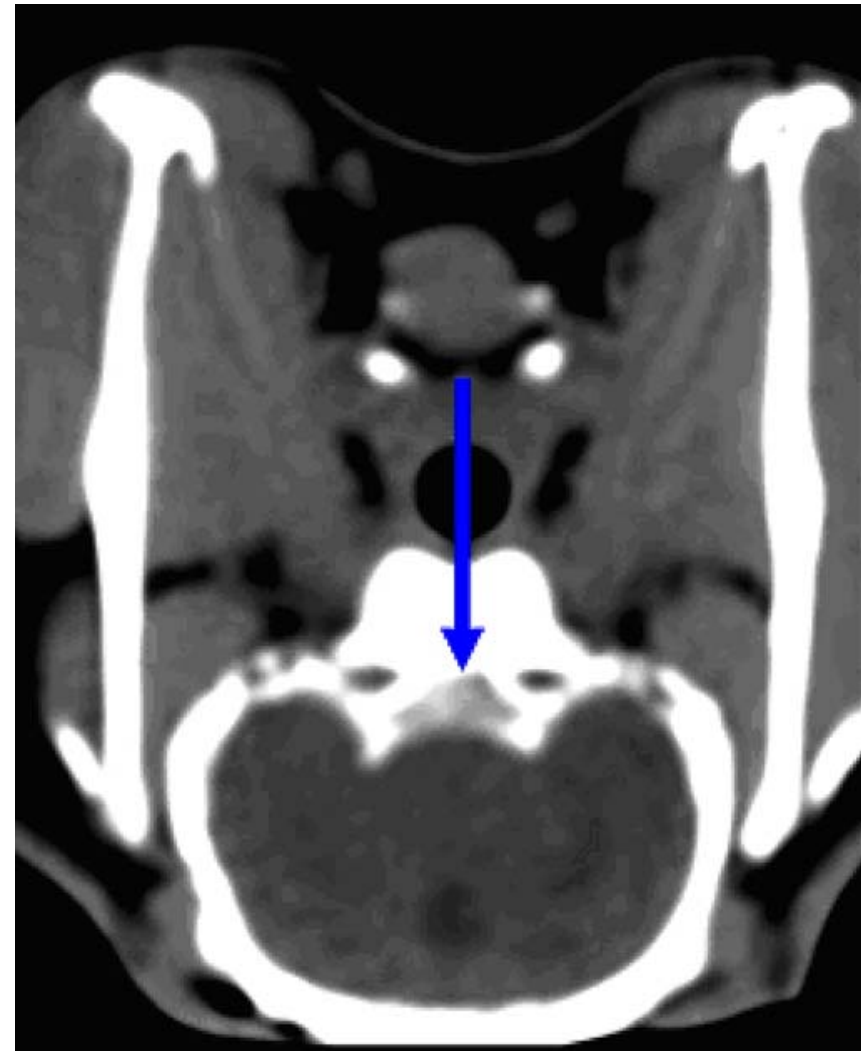

Fig. 1 Axial computer tomography demonstrates the successful dissemination of blood after cisterna magna injection. Arrow, Hyperdense prepontine blood collection

canine models [26, 27]. The rabbit's CSF volume was estimated to be 70-80 times less than that in humans and 5-10 times less than that in dogs [30, 31]. Pumps, associated tubing, and drugs were protected from light at all times. A silicone catheter (STH-C040, Connectors Verbindungstechnik, Tagelswangen, Switzerland) was connected with the pump and inserted at least $1 \mathrm{~mm}$ through the atlanto-occipital membrane into the subarachnoid space. The tube insertion site was sealed by a muscle patch and fixed by several stitches. The midline spinal muscle incision was closed in two layers. Finally, the wounds were superficially irrigated with neomycin sulfate (Research Organics, Cleveland, OH, USA) for infection prophylaxis. All surgical procedures were performed under sterile conditions.

\section{Statistical methods}

Values were expressed as means of each group \pm SEM ( $n=$ number of animals). Statistical significance between two means was determined by Student's unpaired $t$ test and significance between multiple means was determined by analysis of variance. 


\section{Results}

Mortality, morbidity, and neurological status

Two animals died immediately after injection of autologous blood into the atlanto-occipital cistern as a result of respiratory arrest. All other animals were in bland neurological condition after the angiographic and surgical procedures and did not develop delayed neurological deficits, with the exception of one animal in the $\mathrm{SAH} / \mathrm{NaCl}$ control group, which exhibited transient paresis of the hind legs on day 2 after experimental SAH. Clinical daily follow-up of the animals was uneventful up to day 5 when they were killed. Gross pathological evaluation revealed no signs of infection. All of the implanted pump devices were placed in accurate position 1-2 $\mathrm{mm}$ underneath the atlanto-occipital membrane.

\section{Angiographic measurements}

A total of 110 angiographic vessel diameters of the rabbit basilar artery were investigated in the six groups. Angiographic measurements and diameter changes in percentages are given in Table 2 and Fig. 2, respectively. The baseline vessels' diameter on day 0 did not differ significantly among the six experimental groups. The data show that SAH and plain saline infusion were associated with vasoconstriction of the basilar artery $(\mathrm{SAH} / \mathrm{NaCl}$ group $19.85 \pm 2.94 \%$; no $\mathrm{SAH} / \mathrm{NaCl}$ group $14.92 \pm 4.49 \%$; Table 2). The continuous intrathecal infusion of both nimodipine and GTN significantly reduced SAH-associated vasoconstriction $(\mathrm{SAH} /$ nimodipine $0.55 \pm 2.66 \%, n=9$, vs. $\mathrm{SAH} / \mathrm{NaCl} 19.85 \pm 2.94 \%, n=8, p<0.005 ; \mathrm{SAH} / \mathrm{NO}$ $5.93 \pm 5.2 \%, n=11$, vs. SAH/NaCl: $19.85 \pm 2.94 \%, n=8$, $p<0.05)$. The comparison of the effects of nimodipine and GTN on diameter changes after SAH showed no statistical difference.

\section{Discussion}

The results of this study demonstrate nearly complete prevention of delayed CVS of the rabbit basilar artery in response to continuous intrathecal infusion of GTN or

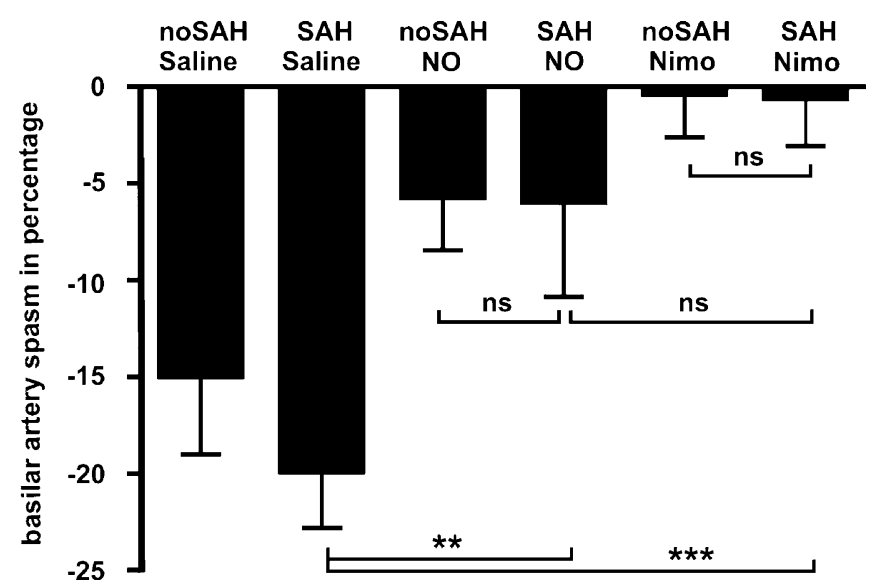

Fig. 2 Bar graph shows the results of the effect of continuous intracisternal administration of nitric oxide donor (nitroglycerin) and nimodipine on cerebral vasospasm after experimental subarrachnoid hemorrhage in rabbits in vivo. The SAH/NO donor group $(n=11)$ and the SAH/nimodipine group $(n=9)$ both demonstrate significant prevention $(* * p=0.0031, * * * p=0.0002)$ of the basilar artery spasm compared to the control SAH/Saline group $(n=8) 5$ days postexperimental subarrachnoid hemorrhage. There was no significant $(p=0.3741)$ difference in the efficacy of spasm reduction between the SAH/NO donor group and the SAH/nimodipine group. There was also no significant difference between the no SAH/NO group $(n=9)$ and the SAH/NO group $(p=0.9622)$ or between the no $\mathrm{SAH} /$ nimodipine $(n=7)$ group and the $\mathrm{SAH} /$ nimodipine group $(p=0.9507)$. Nimo, Nimodipine

nimodipine and therefore confirms previous promising results with intrathecal use of these two compounds [12-17, 24-29, 32]. In the presented experimental setting they showed no significant difference in their efficacy.

NO is the smallest biologically active molecule known. As a highly diffusible gas it mediates an extraordinary range of physiological processes [33, 34]. The role of NO in the context of SAH began when the identity of the hypothetical endothelium-derived relaxing factor and NO was recognized [35-37]. Ongoing research revealed further extensive roles of NO in neurotransmission, inflammation, and vascular autoregulation [38]. In particular NO appears to decrease vascular inflammation (one of the key pathways in delayed CVS) [39, 40], serves as a high potent vasodilating agent [41], and regulates the
Table 2 Summary of the effect of continuous intrathecal nitroglycerin and nimodipine infusion on basilar artery caliber $(\mu \mathrm{m})$ in rabbits with experimental SAH. Values are expressed as the mean \pm standard error of mean

\begin{tabular}{lrllc}
\hline & $n$ & $\begin{array}{l}\text { Diameter }(\mu \mathrm{m}) \\
\text { Day 0 }\end{array}$ & Day 5 & $\begin{array}{l}\text { Diameter } \\
\text { reduction }(\%)\end{array}$ \\
\hline no SAH/NaCl & 11 & $669.51 \pm 2.97$ & $593.59 \pm 3.03$ & $14.92 \pm 4.49$ \\
no SAH/NO & 9 & $676.03 \pm 1.27$ & $625.18 \pm 1.14$ & $5.67 \pm 2.92$ \\
no SAH/nimodipine & 7 & $730.04 \pm 2.60$ & $733.88 \pm 5.90$ & $0.32 \pm 2.30$ \\
SAH/NaCl & 8 & $688.71 \pm 1.81$ & $542.60 \pm 1.70$ & $19.85 \pm 2.94$ \\
SAH/NO & 11 & $648.21 \pm 1.38$ & $637.26 \pm 2.26$ & $5.93 \pm 5.20^{* *}$ \\
SAH/nimodipine & 9 & $726.58 \pm 3.85$ & $713.68 \pm 3.18$ & $0.55 \pm 2.66^{*}$ \\
\hline
\end{tabular}

$* p<0.001, * * p<0.05$ vs. control group $\mathrm{SAH} / \mathrm{NaCl}$ 
cerebral vascular tone as antagonist of the most potent vasoconstrictor ET-1 [42]. Due to the short half-life, side effects, and potential toxicity of NO in clinical use, investigators in the past have focused on treating experimental CVS by using intrathecal and periadventitial soluble administration or polymer placements of $\mathrm{NO}$ and NOD (see Table 1, see ESM) [12-17]. Most of the performed animal studies used diethylenetriamine nitric oxide donor from a controlled release polymer to prevent CVS after experimental SAH [13, 15-17]. Thomas et al. [8] and Kumar et al. [11] published preliminary results of effective treatment of intrathecal bolus administration of SNP in patients with established delayed CVS. Raabe et al. [10] studied the effect of SNP in patients with severe, medically refractory vasospasm. They suggested that SNP is more effective when initiated early and administered continuously.

The highly lipid-soluble calcium antagonist nimodipine has been advocated in the treatment of cerebral vasospasm because it inhibits a fundamental mechanism involved in vasoconstriction of cerebral arteries, calcium influx. The influx of extracellular calcium ions results from the opening of $\mathrm{L}$ type calcium channels (target of calcium antagonists) and additional channels such as store operated-channels [43]. Lack of prevention of CVS and systemic side effects with oral or intravenous administration led to experiments with topical application. Voldby et al. [26] studied the effect of intrathecal bolus administration of calcium antagonist nimodipine after experimental SAH in dogs. Nimodipine always relieved spasm and often the relaxation surpassed the resting vessel diameter, whereas in a control group the injection of placebo did not relax the spastic arteries [26]. Goia et al. [27] and Zabramski et al. [32] found beneficial effect on intrathecal nimodipine as opposed to systemic administration in reversing angiographic vasospasm in the two-hemorrhage and multihemorrhage canine models. Based on these promising data derived from experimental studies on topical nimodipine, first clinical trials have been carried out using perivascular administration of the drug $[24,25,28]$. Despite promising results form these trials and previous experimental studies (Table 2, ESM) [24-29, 32], intrathecal administration of nimodipine as a potential avenue in CVS prevention remained controversial and fall into oblivion [29].

Not only the systemic side effects of current treatment modalities but also the trend towards endovascular treatment of ruptured aneurysms has influenced research into alternatives for treating CVS after SAH [44, 45]. During the procedure of craniotomy and aneurysm clipping the vessels surrounding the bleeding site are accessible for topical drug application or deposition of a polymer or placement of a tube for repeated drug administration. Methods which require surgical access to the region of interest are less likely to be used in a patient treated with endovascular coiling. Other approaches are likely to generate more interest, such as administration through lumbar puncture and advancement of a microcatheter and microguidewire to the ventral cisterna magna under fluoroscopic visualization or administration via conventional external ventricular drain.

In bleeding sites, independently of intrathecal drug application, the ability of the drug to reach the target may be impaired by clotting or abnormal cerebrospinal fluid circulation. Thomas et al. $[8,9]$ argue that the drug (in their experiment SNP) may penetrate the brain parenchyma by way of the ventricle's ependyma. In this hypothesis the drug becomes independent of ventricular CSF circulation but still does not bypass the problem of clot penetration. It remains unclear whether a high drug concentration in close vicinity to the clot is necessary.

In the presented model intrathecal administration is carried out at the same location where the experimental SAH occurred. Nearly all experiments performed are based on this principle of drug administration at the bleeding site. This selectivity is barely conceivable in a clinical setting. Therefore the results from the current study should be evaluated in a model in which the SAH bleeding site is independent of the intrathecal drug administration.

The remarkable vasospasms in the control group (no $\mathrm{SAH} / \mathrm{NaCl}$ ) may have occurred due to aseptic inflammatory response to mechanical disruption [46]. In the beginning of experimental CVS research mechanical stimulation was used to induce arterial narrowing [46, 47]. Other authors with a similar setting of continuous intracisternal drug infusion to attenuate SAH induced CVS do not report a control group of saline infusion and therefore the possibility to compare our findings lacks [48]. However, the results indicate that the placement of drug administration devices in the vicinity of the examined vessel could be unfavorable. Independent location of drug administration from the bleeding site would avoid any local interaction and drug penetration to the affected vessel could be determined. Eligible would be the use of a ventriculosubarachnoid cannula, with the possibility of continuous drug administration and simultaneous measurement of intracranial pressure through the same cranial screw device [49]. In this set-up possible side effects of additional fluid derived from drug administration can be monitored by the ICP parameter.

The results show no statistically significant difference between no SAH/treatment and SAH/treatment groups, which indicates that both nimodipine and GTN are potent in preventing delayed cerebral vasospasm associated with either experimental SAH or pump implantation. In the current understanding of delayed cerebral vasospasm nimodipine and NO donor GTN are acting at the bottom of the pathophysiological cascade and may prevent vasospasm on an unspecific basis, irrespective of the initially underlying cause (chemical stimulation by subarachnoid blood or mechanical stimulation by pump implantation). 
The findings of this study warrant further investigations into the dose-dependency effects of continuous intrathecal infusion NO donors and nimodipine in a modified rabbit model with intraventricular drug delivery. Based on current clinical treatment modalities after SAH, an experimental setting with an intrathecal administration site that differs from the bleeding site is needed to confirm these results as a potential preventive treatment option in SAH-associated CVS.

Acknowledgements. We gratefully thank Hans Rudolf Widmer, $\mathrm{PhD}$, and Jürgen Schmid, RN, from the Department of Neurosurgery, University Hospital Berne, for their professional laboratory support.

\section{References}

1. Brisman JL, Song JK, Newell DW (2006) Cerebral aneurysms. N Engl J Med 355:928-939

2. Al-Yamany M, Wallace MC (1999) Management of cerebral vasospasm in patients with aneurysmal subarachnoid hemorrhage. Intensive Care Med 25:1463-1466

3. Biller J, Godersky JC, Adams HP Jr (1988) Management of aneurysmal subarachnoid hemorrhage. Stroke 19:1300-1305

4. Sen J, Belli A, Albon H, Morgan L, Petzold A, Kitchen N (2003) Triple-H therapy in the management of aneurysmal subarachnoid haemorrhage. Lancet Neurol 2:614-621

5. Porchet F, Chiolero R, de Tribolet N (1995) Hypotensive effect of nimodipine during treatment for aneurysmal subarachnoid haemorrhage. Acta Neurochir (Wien) 137:62-69

6. Stiefel MF, Heuer GG, Abrahams JM, Bloom S, Smith MJ, MaloneyWilensky E, Grady MS, LeRoux PD (2004) The effect of nimodipine on cerebral oxygenation in patients with poor-grade subarachnoid hemorrhage. J Neurosurg 101:594-599

7. Subramani K, Ghrew M (2004) Severe myocardial depression following intravenous nimodipine for aneurysmal subarachnoid haemorrhage. Intensive Care Med 30:1498-1499

8. Thomas JE, Rosenwasser RH, Armonda RA, Harrop J, Mitchell W, Galaria I (1999) Safety of intrathecal sodium nitroprusside for the treatment and prevention of refractory cerebral vasospasm and ischemia in humans. Stroke 30:1409-1416

9. Thomas JE, Rosenwasser RH (1999) Reversal of severe cerebral vasospasm in three patients after aneurysmal subarachnoid hemorrhage: initial observations regarding the use of intraventricular sodium nitroprusside in humans. Neurosurgery 44:48-57
10. Raabe A, Zimmermann M, Setzer M, Vatter H, Berkefeld J, Seifert V (2002) Effect of intraventricular sodium nitroprusside on cerebral hemodynamics and oxygenation in poor-grade aneurysm patients with severe, medically refractory vasospasm. Neurosurgery 50:1006-1013

11. Kumar R, Pathak A, Mathuriya SN, Khandelwal N (2003) Intraventricular sodium nitroprusside therapy: a future promise for refractory subarachnoid hemorrhage-induced vasospasm. Neurol India 51:197-202

12. Wolf EW, Banerjee A, Soble-Smith J, Dohan FC Jr, White RP, Robertson JT (1998) Reversal of cerebral vasospasm using an intrathecally administered nitric oxide donor. J Neurosurg 89:279-288

13. Gabikian P, Clatterbuck RE, Eberhart CG, Tyler BM, Tierney TS, Tamargo RJ (2002) Prevention of experimental cerebral vasospasm by intracranial delivery of a nitric oxide donor from a controlled-release polymer: toxicity and efficacy studies in rabbits and rats. Stroke 33:2681-2686

14. Aihara Y, Jahromi BS, Yassari R, Sayama T, Macdonald RL (2003) Effects of a nitric oxide donor on and correlation of changes in cyclic nucleotide levels with experimental vasospasm. Neurosurgery 52:661-667

15. Pradilla G, Thai QA, Legnani FG, Hsu W, Kretzer RM, Wang PP, Tamargo RJ (2004) Delayed intracranial delivery of a nitric oxide donor from a controlled-release polymer prevents experimental cerebral vasospasm in rabbits. Neurosurgery 55:1393-1399

16. Clatterbuck RE, Gailloud P, Tierney T, Clatterbuck VM, Murphy KJ, Tamargo RJ (2005) Controlled release of a nitric oxide donor for the prevention of delayed cerebral vasospasm following experimental subarachnoid hemorrhage in nonhuman primates. J Neurosurg 103:745-751
17. Tierney TS, Pradilla G, Wang PP, Clatterbuck RE, Tamargo RJ (2006) Intracranial delivery of the nitric oxide donor diethylenetriamine/nitric oxide from a controlled-release polymer: toxicity in cynomolgus monkeys. Neurosurgery 58:952-960

18. Suzuki Y, Osuka K, Noda A, Tanazawa T, Takayasu M, Shibuya M, Yoshida J (1997) Nitric oxide metabolites in the cisternal cerebral spinal fluid of patients with subarachnoid hemorrhage. Neurosurgery 41:807-811

19. Thomas JE, Nemirovsky A, Zelman V, Giannotta SL (1997) Rapid reversal of endothelin-1-induced cerebral vasoconstriction by intrathecal administration of nitric oxide donors. Neurosurgery 40:1245-1249

20. Macdonald RL, Zhang ZD, Curry D, Elas M, Aihara Y, Halpern H, Jahromi BS, Johns L (2002) Intracisternal sodium nitroprusside fails to prevent vasospasm in nonhuman primates. Neurosurgery 51:761-768

21. Pickard JD, Murray GD, Illingworth R, Shaw MD, Teasdale GM, Foy PM, Humphrey PR, Lang DA, Nelson R, Richards P et al. (1989) Effect of oral nimodipine on cerebral infarction and outcome after subarachnoid haemorrhage: British aneurysm nimodipine trial. BMJ 298:636-642

22. Tettenborn D, Dycka J, Volberg E, Dudden P (1985) Blood pressure and heart rate during treatment with nimodipine in patients with subarachnoid hemorrhage. Neurochirurgia (Stuttg) 28 [Suppl 1]:84-86

23. Tettenborn D, Dycka J (1990) Prevention and treatment of delayed ischemic dysfunction in patients with aneurysmal subarachnoid hemorrhage. Stroke 21:IV85-IV89

24. Auer LM, Ito Z, Suzuki A, Ohta H (1982) Prevention of symptomatic vasospasm by topically applied nimodipine. Acta Neurochir (Wien) 63:297-302 
25. Auer LM (1984) Acute operation and preventive nimodipine improve outcome in patients with ruptured cerebral aneurysms. Neurosurgery 15:57-66

26. Voldby B, Petersen OF, Buhl M, Jakobsen P, Ostergaard R (1984) Reversal of cerebral arterial spasm by intrathecal administration of a calcium antagonist (nimodipine). Acta Neurochir (Wien) 70:243-254

27. Gioia AE, White RP, Bakhtian B, Robertson JT (1985) Evaluation of the efficacy of intrathecal nimodipine in canine models of chronic cerebral vasospasm. J Neurosurg 62:721-728

28. Auer LM, Brandt L, Ebeling U, Gilsbach J, Groeger U, Harders A, Ljunggren B, Oppel F, Reulen HJ, Saeveland H (1986) Nimodipine and early aneurysm operation in good condition SAH patients. Acta Neurochir (Wien) 82:7-13

29. Lewis PJ, Weir BK, Nosko MG, Tanabe T, Grace MG (1988) Intrathecal nimodipine therapy in a primate model of chronic cerebral vasospasm. Neurosurgery 22:492-500

30. Artru AA, Momota T (2000) Rate of CSF formation and resistance to reabsorption of CSF during sevoflurane or remifentanil in rabbits. J Neurosurg Anesthesiol 12:37-43

31. Zoghbi HY, Okumura S, Laurent JP, Fishman MA (1985) Acute effect of glycerol on net cerebrospinal fluid production in dogs. J Neurosurg 63:759-762

32. Zabramski J, Spetzler RF, Bonstelle C (1986) Chronic cerebral vasospasm: effect of calcium antagonists. Neurosurgery 18:129-135
33. Nathan C, Xie QW (1994) Nitric oxide synthases: roles, tolls, and controls. Cell 78:915-918

34. Koshland DE Jr (1992) The molecule of the year. Science 258:1861

35. Hanggi D, Steiger HJ (2006) Nitric oxide in subarachnoid haemorrhage and its therapeutics implications. Acta Neurochir (Wien) 148:605-613

36. Kim P, Lorenz RR, Sundt TM Jr, Vanhoutte PM (1989) Release of endothelium-derived relaxing factor after subarachnoid hemorrhage. J Neurosurg 70:108-114

37. Marin J, Sanchez-Ferrer CF (1990) Role of endothelium-formed nitric oxide on vascular responses. Gen Pharmacol 21:575-587

38. Anggard E (1994) Nitric oxide: mediator, murderer, and medicine. Lancet 343:1199-1206

39. Berendji-Grun D, Kolb-Bachofen V, Kroncke KD (2001) Nitric oxide inhibits endothelial IL-1[beta]-induced ICAM-1 gene expression at the transcriptional level decreasing Sp1 and AP-1 activity. Mol Med 7:748-754

40. Oshiro EM, Hoffman PA, Dietsch GN, Watts MC, Pardoll DM, Tamargo RJ (1997) Inhibition of experimental vasospasm with anti-intercellular adhesion molecule-1 monoclonal antibody in rats. Stroke 28:2031-2037

41. Pluta RM (2005) Delayed cerebral vasospasm and nitric oxide: review, new hypothesis, and proposed treatment. Pharmacol Ther 105:23-56

42. Faraci FM (1990) Role of nitric oxide in regulation of basilar artery tone in vivo. Am J Physiol 259:H1216-H1221
43. Zuccarello M, Boccaletti R, Tosun M, Rapoport RM (1996) Role of extracellular $\mathrm{Ca} 2+$ in subarachnoid hemorrhage-induced spasm of the rabbit basilar artery. Stroke 27:1896-1902

44. Molyneux AJ, Kerr RS, Yu LM, Clarke M, Sneade M, Yarnold JA, Sandercock P (2005) International subarachnoid aneurysm trial (ISAT) of neurosurgical clipping versus endovascular coiling in 2143 patients with ruptured intracranial aneurysms: a randomised comparison of effects on survival, dependency, seizures, rebleeding, subgroups, and aneurysm occlusion. Lancet 366:809-817

45. Citerio G, Gaini SM, Tomei G, Stocchetti N (2007) Management of 350 aneurysmal subarachnoid hemorrhages in 22 Italian neurosurgical centers. Intensive Care Med 33:1580-1586

46. Blaumanis OR, Grady PA (1982) Experimental cerebral vasospasm: resolution by chlorpromazine. Surg Neurol 17:263-268

47. Endo S, Suzuki J (1979) Experimental cerebral vasospasm after subarachnoid hemorrhage. Participation of adrenergic nerves in cerebral vessel wall. Stroke 10:703-711

48. Zuccarello M, Boccaletti R, Romano A, Rapoport RM (1998) Endothelin B receptor antagonists attenuate subarachnoid hemorrhage-induced cerebral vasospasm. Stroke 29:1924-1929

49. Gyring JA, Brondsted HE (1984) Repetitive measurements of intracranial pressure in awake rabbits. Acta Physiol Scand 122:299-305 